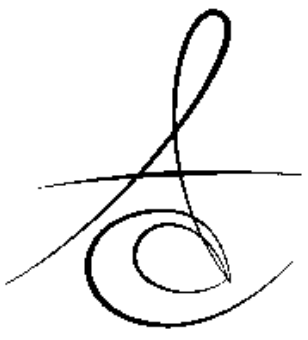

\title{
FARKLI ÜNİVERSAL BAĞLAYICI AJANLARIN CAD/CAM SERAMİKLERİN KOMPOZİT REZİN İLE TAMİRİ SONRASI BAĞLANMA KUVVETİNE ETKİSİ ${ }^{*}$
}

\author{
THE EFFECT OF DIFFERENT UNIVERSAL BONDING AGENTS ON THE BOND \\ STRENGTH OF CAD/CAM CERAMICS REPAIRED WITH COMPOSITE RESIN ${ }^{*}$
}

\author{
Arş. Gör. Kübra CANTÜRK* \\ Dr. Öğr. Üyesi Ömer SAĞSÖZ* \\ Dr. Öğr. Üyesi Nurdan POLAT SAĞSÖz**
}

\author{
Arş. Gör. Buket KARALAR* \\ Prof. Dr. Nilgün SEVEN* \\ Prof. Dr. Yusuf Ziya BAYINDIR*
}

Makale Kodu/Article code: 3824

Makale Gönderilme tarihi; 20.09 .2018

Kabul Tarihi: 18.02 .2019

\section{öz}

Amaç: Bu çalışmada iki farklı CAD/CAM seramiğe bir primer ve iki farklı bağlayıcı ajan uygulanarak kompozit rezinle tamir sonrası bağlanma kuvvetinin değerlendirilmesi amaçlandı.

Yöntem: CAD/CAM seramik materyallerden (VITA Suprinity ve IPS e.max CAD) 30'ar adet örnek hazırlandı. Örnekleri elde etmek için yavaş hızı testere (ISOMET 1000) kullanılarak seramik bloklardan $1 \mathrm{~mm}$ kalınlığında kesitler alındı. Daha sonra seramikler soğuk akriliğe sabitlenerek yüzeylerine $1 \mathrm{dk}$ boyunca \%10'luk hidroflorik asit uygulandı. Primer uygulamasına göre seramikler iki gruba ayrıldı: BISCO Z-Prime-ZP ve primer kullanılmayan kontrol grubu-K. Uygulanan bağlayıc ajanlara göre de seramikler 2 alt gruba daha ayrıldı: 3M ESPE Single Bond Universal-Sb, KURARAY Clearfil Universal Bond Quick-Qb $(n=5) .3 M$ ESPE Single Bond Universal-Sb seramiklere 20 sn boyunca ovalama hareketi ile uygulanıp 5 sn hava ile seyreltildi ve LED ışık cihazı ile 10 sn polimerize edildi. KURARAY Clearfil Universal Bond Quick-Qb ise seramiklere 10 sn boyunca ovalama hareketi ile uygulanıp 5 sn hava ile seyreltildi ve LED ısıı cihazı ile $10 \mathrm{sn}$ polimerize edildi. Bir kompozit rezin (VOCO Xtra-fil) $4 \mathrm{~mm}$ çapında ve $4 \mathrm{~mm}$ yüksekliğinde plastik kalıplar kullanılarak bir LED ışık cihazı ile seramik yüzeylerde polimerize edildi. Elde edilen örnekler 24 saat $37^{\circ} \mathrm{C}$ saf suda bekletildi. Bağlanma kuvvetleri bir universal test cihazı kullanılarak makaslama testi ile ölçüldü. Kaydedilen değerler tek yönlü varyans analizi (ANOVA) kullanılarak analiz edildi $(p<0.05)$. Kırılma tipleri bir stereo mikroskop yardımıyla tespit edildi.

Bulgular: En yüksek bağlanma dayanımı Suprinity+K+Qb (20.15 MPa) grubunda, en düşük bağlanma dayanımı e.max $C A D+Z P+Q b(10.85 \mathrm{MPa})$ grubunda bulundu. Primer ve bağlayıcı ajanlar arasında herhangi bir fark bulunmazken ( $p>0.05)$, seramikler arasında önemli derecede fark bulundu $(p<0.05)$. e.max CAD örneklerin bağlanma değerleri Suprinity ye göre anlamlı derecede daha düşük bulundu $(p<0.05)$.

Sonuç: Bu çalışmanın sınırları dahilinde; üniversal bağlayıc ajanların tek başına kullanıldığı kontrol grubunun, BISCO ZPrime Plus kullanılan gruplara benzer bağlanma sonuçları gösterdiği ve iki uygulamanın da klinik olarak yeterli bağlanma dayanımı sağladıkları belirlenmiştir. Üniversal bağlayıc ajanlar, CAD/CAM seramiklerin kompozit rezin ile tamirinde klinik olarak tek başlarına kullanılabilir.

Anahtar Kelimeler: Bağlanma Kuvveti, Kompozit, Üniversal Bond, Seramik

\section{ABSTRACT}

Aim: In this study, a primer and two bonding agents were used on two different CAD / CAM ceramics to evaluate the bond strength after repairing with composite resin.

Methods: 30 samples were prepared from CAD/CAM ceramic materials (VITA Suprinity and IPS e.max CAD). $1 \mathrm{~mm}$ thick sections were cut from the ceramic blocks using a low speed diamond saw (ISOMET 1000) to obtain the samples. Then the ceramics were fixed to with cold cured acrylic and the surfaces were treated with $10 \%$ hydrofluoric acid for $1 \mathrm{~min}$. According to the primer application, ceramics were divided into two groups: BISCO Z-Prime-ZP and control group without primer-K. According to the bonding agents applied, ceramics were further divided into 2 subgroups: 3M ESPE Single Bond Universal-Sb and KURARAY Clearfil Universal Bond Quick-Qb $(n=5)$. 3M ESPE Single Bond Universal-Sb was applied to ceramics with a scrubbing for 20 seconds and thinned with air for 5 seconds and polymerized with LED device for 10 seconds. KURARAY Clearfil Universal Bond Quick-Qb was applied to ceramics with a scrubbing for 10 seconds and thinned with air for 5 seconds and polymerized with LED device for 10 seconds. A composite resin (VOCO Xtra-fil) was polymerized on ceramic surfaces with a LED device using $4 \mathrm{~mm}$ diameter and $4 \mathrm{~mm}$ height plastic molds. The obtained samples were stored for 24 hours at $37^{\circ}$ $C$ in distilled water. Bond strength values were measured by a shear bond test using a universal tester. The recorded values were analyzed using Univariate Analysis of Variance (ANOVA). $(p<0.05)$ The fracture types were detected using a stereo microscope.

Results: The highest bond strength was found in the group Suprinity + K + Qb (20.15 MPa), with the lowest bond strength in the group of e.max CAD + ZP + Qb (10.85 MPa). There was no significant difference between the primer groups and bonding agent groups ( $p>0.05)$, but there was a significant difference between the ceramics $(p<0.05)$. The bond strength values of e.max CAD samples were significantly lower than Suprinity samples. $(p<0.05)$

Conclusion: Within the limits of this study; The control group using the universal bonding agents were shown to exhibit similar bonding results to those group used BISCO Z-Prime Plus and that both applications provided clinically sufficient bond strength. Universal bonding agents can be used alone in the clinical repair of CAD/CAM ceramics with composite resin.

Keywords: Bond Strength, Ceramics, Composite, Universal Bond

Atatürk Universitesi, Diş Hekimliği Fakültesi, Restoratif Diş Tedavisi AD, Erzurum.

${ }^{* *}$ Atatürk Üniversitesi, Diş Hekimliği Fakültesi, Protetik Diş Tedavisi AD, Erzurum.

${ }^{*}$ Bu çalışma Restoratif Diş Hekimliği Derneğinin (RDD) 21.Uluslararası Bilimsel Kongresinde (1-3 Aralık 2017, Eskişehir, Türkiye) poster olarak sunulmuştur.

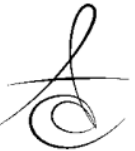




\section{GİRİ̧̧}

Gelişen teknolojiyle beraber geçmişten günümüze, restoratif diş hekimliğinin en önemli amaçlarından biri kaybedilmiş olan diş dokularının bütünlüğünün tekrar sağlanması, fonksiyon ve fonasyonun iadesi ile estetiğin temin edilmesi olmuştur. Bu amaçla estetik ve biyouyumlu yapılarından dolayı tam seramik restorasyonların diş hekimliğinde önemli bir yere sahip olduğu söylenebilir. Günümüzde, bilgisayar destekli tasarım ve bilgisayar destekli üretim (CAD/CAM) teknolojisi sayesinde, hasta başında veya laboratuvar ortamında, restorasyonların daha hızlı üretilmesine olanak sağlanmıştır ve bu teknoloji geleneksel tekniklere alternatif olarak sıkça kullanılmaya başlanmıştır. ${ }^{1}$

Seramik malzemelerin kırılmaya eğilimli olduğu bilinmektedir. Yapılan çalışmalar da yükleme noktalarının kırılmaya eğilimi arttırdığı gösterilmiştir; molar ve premolar için okluzal yüzeyler veya kesiciler için palatinal yüzeyler örnek olarak verilebilir. Wang ve arkadaşları ${ }^{2}, 5$ yıllık takiple yapılan bir klinik çalışmada tüm seramik restorasyonları \% 4,4'lük bir kırılma oranının olduğunu göstermiştir. İndirekt restorasyonların kırılma direnci ve kullanım süresi ağız koşullarının (sıcaklık değişiklikleri, çiğneme basıncı, vb.) değişmesi ile azalır. ${ }^{3}$ CAD/CAM seramik restorasyonların 5 yıl (\% 97) ve 10 yı (\% 90) süresince sağ kalma oranları vardır. ${ }^{4}$

Seramik restorasyonlarda klinik olarak sık gözlenen başarısızlıklardan bir tanesi de bölgesel kısmi kırıklardır. ${ }^{5} \mathrm{Bu}$ durumda ya restorasyon yenilenir ya da tercihen ağız içinde tamir edilme yoluna gidilir. Klinik vakaların bir çoğunda dişte meydana gelebilecek travma nedeniyle var olan restorasyonun yenilenmesi doğru bir tercih olmayabilir. ${ }^{6}$

Setcos ve arkadaşları ${ }^{7}$ tarafından kusurlu restorasyonlar için bazı tedavi yaklaşımları önerilmiştir: (1) tedavi etmemek (izlemek), (2) yenilemek (restoratif materyal eklemeden), (3) onarmak (restoratif materyalin eklenmesi), ve (4) değiştirmek. Seramik restorasyonların dişe zarar vermeden çıkarılması veya restorasyonun zarar görmeden çıkarılması genellikle mümkün değildir. Dolayısıyla çatlak ve kırıkların büyüklüğüne bağlı olarak, intraoral adeziv tamir prosedürleri kullanılabilir. Porselen restorasyonların, kompozit rezinlerle ağız içinde tamirinde çıkarılmalarına gerek yoktur. Bu nedenle lokal kırıklar için, restorasyonun yenilenmesine alternatif olarak ağız içinde tamir de düşünülebilir.
Son zamanlarda klinikte kullanımı kolaylaştıran tek aşamalı self-etch adezivlerin dezavantajlarını ortadan kaldırmaya yönelik araştırmalar sonucunda "Universal" veya "Multi mode" olarak isimlendirilen adeziv ajanlar piyasaya sunulmuştur. ${ }^{8}$ Bu ürünler hem self-etch, hem minenin selektif asitlenmesi, hem de etch\&rinse olarak uygulanabilmektedirler. Universal adeziv ajanların geniş endikasyon yelpazesi bulunmaktadır. Tüm kompozit rezin ve kompomer restorasyonların adezyonunda, venerlerin simantasyonunda, indirekt restorasyonların geçici olarak simantasyonundan önce diş dokularının örtülenmesinde, var olan kompozit rezin, metal alt yapılı porselen ya da tam seramik restorasyonların ağız içindeki tamirlerinde kullanılabilir.

Genel anlamda ağız içinde tamir işlemi kırık yüzeyin hazırlanması ve kompozit rezinlerle restorasyonun kırılan kısmının tamamlanmasına dayanmaktadır. Tamir işleminin klinik başarısı büyük ölçüde yüzeyde pürüzlülük meydana getirmek için yapılan yüzey hazırlıkları sonrasında restorasyon ile kompozit rezin arasında oluşan mekanik veya kimyasal bağlantının bütünlüğünün korunmasına bağlıdır. ${ }^{9}$ Geleneksel olarak seramik restorasyonlar için yapılan yüzey hazırlıkları hidroflorik asit ile pürüzlendirme, silan uygulamaları, alüminyum oksit partikülleri ile kumlama, tribokimyasal silika kaplaması ve frez ile mekanik pürüzlendirme olarak sıralanabilir. ${ }^{9,10}$

Seramik blokların, rezin kompozitlerle bağlayıcı ajan kullanılarak ağız içinde tamir edilmesine dair yapılan sınırlı sayıda çalışma bulunmaktadır. Bu çalışmadaki amaç; iki farklı CAD/CAM seramik bloğa bir primer ve iki farklı bağlayıc ajan uygulanarak kompozit rezinle tamir sonrası bağlanma kuvvetinin değerlendirilmesidir. Çalışmamızın sıfır hipotezi primer kulanımının farklı universal bağlayıcı ajanlar kullanılarak seramiklerin kompozit rezin ile tamirinde bağlanma dayanımına herhangi bir etkisi yoktur olarak kurulmuştur.

\section{MATERYAL METOD}

CAD/CAM seramik materyallerden (VITA Suprinity (VITA, Zahnfabrik, BadSackingen, Almanya) ve IPS e.max CAD (IPS e.max CAD; Ivoclar Vivadent, Amherst, NY, ABD) 30'ar adet örnek hazırlandı. Örnekleri elde etmek için yavaş hızlı testere (Isomet Low Speed Saw1000; Buehler, Lake Buff, IL, ABD)

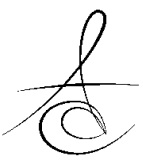


kullanılarak seramik bloklardan $1 \mathrm{~mm}$ kalınlığında kesitler alındı. CAD/CAM seramik bloklara üreticinin talimatları doğrultusunda kristalizasyon işlemi uygulandı ve bloklar daha dirençli hale getirildi. Daha sonra seramikler soğuk akriliğe sabitlenerek yüzeylerine 1dk boyunca hidroflorik asit (HF) (Dentobond porcelainfix, ITENA, Paris, Fransa) uygulandı. Primer uygulamasına göre seramikler iki gruba ayrıldı: Z-Prime Plus (BISCO, Inc. Schaumburg, IL, ABD) ve primer kullanılmayan kontrol grubu. Uygulanan bağlayıcı ajanlara göre de seramikler 2 alt gruba daha ayrıldı: Single Bond Universal (3M ESPE, St. Paul MN, ABD), Clearfil Universal Bond Quick ( Kuraray Noritake Dental Inc., Tokyo, Japonya) $(n=5)$. Bir kompozit rezin (VOCO Xtra-fil-VOCO, Cuxhaven, Niedersachsen, Almanya) 4 $\mathrm{mm}$ çapında ve $4 \mathrm{~mm}$ yüksekliğinde plastik kalıplar kulanılarak bir LED cihazı (Woodpecker LED-D Işık cihazı, GuilinWoodpecker Medikal Endüstri, Ltd, Guangxi, Çin, $850-1000 \mathrm{~mW} / \mathrm{cm}^{2}$ ) ile seramik yüzeylerde 20 sn polimerize edildi. Elde edilen örnekler 24 saat $37^{\circ} \mathrm{C}$ saf suda bekletildi. Makaslama bağlanma dayanımı değerleri üniversal bir test cihazı (Instron 3344, Instron Corp, Wilmington, ABD) kullanılarak ölçüldü. Üniversal test cihazının başlık hızı $1 \mathrm{~mm} / \mathrm{dk}$ olarak ayarlandı. Kaydedilen değerler tek yönlü varyans analizi (ANOVA) kullanılarak analiz edildi $(p<0.05)$. Kırılma yüzeyleri $20 x$ büyütmede stereo mikroskopta (Olympus SZ4045 TRPT, Osaka, Japonya) incelendi. Kırılma yüzeyleri bağlantı yüzeylerinin başarısızlık tipine göre değerlendirildi.

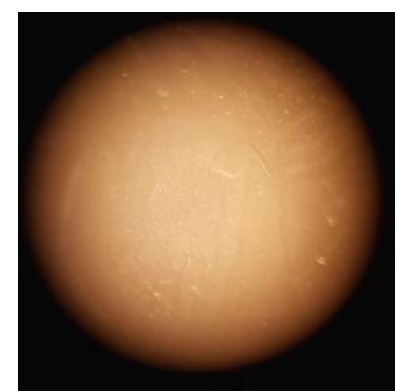

Resim 1. Adeziv Başarısızlık

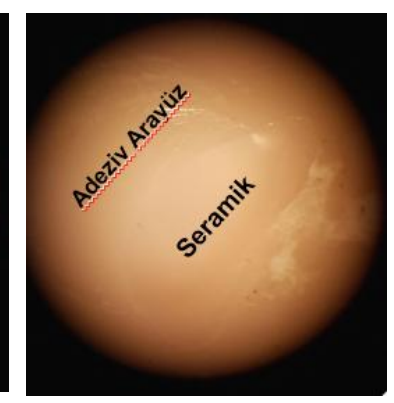

Resim 2. Miks Başarısızlık

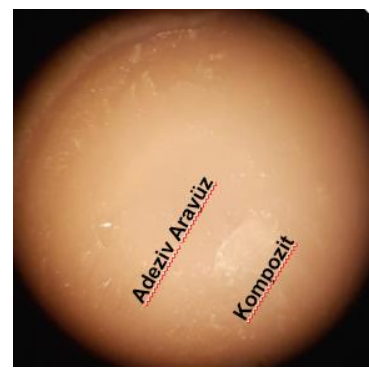

Resim 3. Miks Başarısızlık

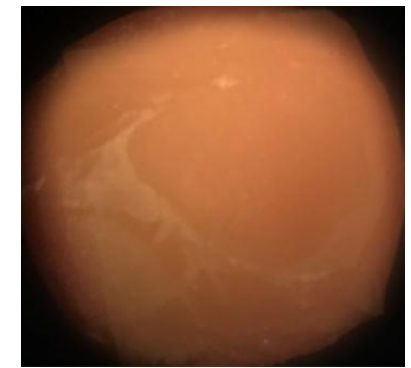

Resim 4. Seramik Koheziv Başarısızlık

\section{BULGULAR}

Örneklerin makaslama bağlanma dayanımı değerleri (MPa) ve kırılma tipleri Tablo I'de gösterilmiştir. Primer kullanımı $(p=0.265)$ ve bağlayıcı ajanlar $(p=0.779)$ arasında herhangi bir fark bulunmazken, seramik CAD/CAM bloklar arasında önemli derecede fark bulundu $(p<0.05)$.

Fark bulunan seramik gruplarının ortalama ve standart sapma değerlerine dayalı olarak çalışmanın etki gücü 1.15 olarak hesaplandı. $a=0.05$ ve güç(1$\beta)=0.80$ öngörüldüğü zaman her grupta olması gereken en düşük örnek sayısı 13 olarak hesaplandı. Çalışmada ise her bir seramik için 20 örnek kullanılması durumuna göre etki büyüklüğü ve 0.05 hata düzeyinde testin gücü 0.94 olarak hesaplandı.

Çalışmada e.max CAD örneklerin bağlanma değerleri Suprinity'ye göre istatistiksel olarak anlamlı derecede düşük bulundu $(p<0.05)$.

\begin{tabular}{|c|c|c|c|c|c|}
\hline \multirow[t]{2}{*}{ SERAMİK } & \multirow[t]{2}{*}{ PRIMER } & \multicolumn{2}{|c|}{ BAĞLAYICI AJAN (MPa) } & \multicolumn{2}{|c|}{ KIRILMA TİPLERİ } \\
\hline & & $\begin{array}{c}\text { SINGLE } \\
\text { BOND } \\
\text { UNIVERSAL } \\
(\mathrm{n}=5) \\
\end{array}$ & $\begin{array}{c}\text { UNIVERSAL } \\
\text { BOND } \\
\text { QUICK } \\
(n=5)\end{array}$ & $\begin{array}{c}\text { SINGLE BOND } \\
\text { UNIVERSAL } \\
(n=5)\end{array}$ & $\begin{array}{c}\text { UNIVERSAL } \\
\text { BOND } \\
\text { QUICK } \\
(\mathrm{n}=5) \\
\end{array}$ \\
\hline \multirow[b]{2}{*}{$\begin{array}{c}\text { VITA } \\
\text { Suprinity }\end{array}$} & $\begin{array}{c}\text { Z-prime } \\
\text { Plus }\end{array}$ & $\begin{array}{c}16.11 \pm \\
4.68^{\mathrm{a}}\end{array}$ & $\begin{array}{c}15.38 \pm \\
2.53^{\mathrm{a}}\end{array}$ & $\begin{array}{c}\% 60 \text { Adeziv } \\
\% 20 \text { Miks } \\
\% 20 \text { Seramik } \\
\text { Koheziv } \\
\end{array}$ & $\begin{array}{l}\% 60 \text { Adeziv } \\
\% 40 \text { Miks }\end{array}$ \\
\hline & Kontrol & $\begin{array}{c}14.36 \pm \\
6.22^{\mathrm{a}}\end{array}$ & $\begin{array}{c}20.15 \pm \\
3.95^{\mathrm{a}}\end{array}$ & $\begin{array}{l}\% 40 \text { Adeziv } \\
\% 40 \text { Miks } \\
\% 20 \text { Seramik } \\
\text { Koheziv }\end{array}$ & $\begin{array}{c}\text { \%20 Adeziv } \\
\% 60 \text { Miks } \\
\% 20 \\
\text { Seramik } \\
\text { Koheziv }\end{array}$ \\
\hline \multirow[b]{2}{*}{$\begin{array}{l}\text { IPS e.max } \\
\text { CAD }\end{array}$} & $\begin{array}{c}\text { Z-prime } \\
\text { Plus }\end{array}$ & $\begin{array}{c}11.60^{ \pm} \\
4.20^{\mathrm{b}} \\
\end{array}$ & $\begin{array}{c}10.85 \pm \\
2.33^{\mathrm{b}} \\
\end{array}$ & \%100 Adeziv & $\begin{array}{c}\% 100 \\
\text { Adeziv }\end{array}$ \\
\hline & Kontrol & $\begin{array}{c}14.01 \pm \\
2.79^{\mathrm{b}}\end{array}$ & $\begin{array}{c}11.13 \pm \\
3.12^{\mathrm{b}}\end{array}$ & $\begin{array}{c}\text { \%80 Adeziv } \\
\% 20 \text { Seramik } \\
\text { Koheziv }\end{array}$ & $\begin{array}{c}\% 60 \text { Adeziv } \\
\% 40 \text { Miks }\end{array}$ \\
\hline
\end{tabular}




\section{TARTIŞMA}

Başarısız bir restorasyonun değiştirilmesi; maliyeti ve kalan diş yapısında oluşturulacak ek travma dikkate alınacak olursa her zaman en pratik çözüm değildir. Kırık bir seramik restorasyonun onarımı zorlu bir klinik durumdur ve onarımların klinik performansı hakkında çok az sayıda çalışma bulunmaktadır. Seramiklerin tamiri için önerilen klinik prosedürler; zarar gören yüzeyin pürüzlendirilmesi ve o yüzeylerde seramik tamir materyallerinin kullanılmasıdır. ${ }^{11,}{ }^{12}$ Tamir için materyal seçiminde kompozit rezinler; iyi estetik sağlamaları, düşük maliyetleri ve kolay manipüle edilebilmelerinden dolayı iyi bir seçenektir.

Colares ve arkadaşları ${ }^{13}$ seramik restorasyonların kompozit rezinlerle tamirinde lityum disilikat seramiklerin yüzeylerinin HF asit ve silan uygulamasıyla ön hazırlığının yapılmasının alternatif bir yöntem olduğunu; ancak kumlama ile yüzey ön hazırlığından kaçınımasını gerektiğini göstermiştir. Düzyol ve arkadaşlarının ${ }^{14}$ çalışmalarında, kumlama yapılmış IPS e.max CAD seramiklerin kompozit (Filtek Z 550, 3M ESPE) ile tamirinde mikrotensile bağlanma dayanımı başarısız olarak değerlendirilmiştir.

Kupiec ve arkadaşları ${ }^{15}$ asit kullanılmayan porselen (Ceramco II) örneklere kıyasla HF asit uygulanmış örneklerin makaslama bağlanma dayanımının daha yüksek olduğunu göstermiştir. Hem airborne partikül aşınması hem de HF' in seçici olarak zayıf camsı fazı çözdüğü ve lityum disilikat kristallerini açığa çıkardığı bilinmektedir; her ikisi de retantif özelliği arttırır. Porözlü düzensiz yüzeyler işlenmiş seramik yüzeylerin mikroretansiyonunda rezinin penetrasyonunu kolaylaştırır. ${ }^{16,17}$ Üreticileri $\% 10$ zirkonya içeriğe sahip Suprinity ve lityum disilikat seramik olan e.max CAD için HF asit ile yüzeyin hazırlanmasını tavsiye etmektedir. $\mathrm{Bu}$ sebeplerle çalışmada yüzeylere $\mathrm{HF}$ asit uygulaması gerçekleştirildi.

Tekniğe bakılmaksızın makaslama bağlanma dayanımının ölçülmesi, dental adezyonda tartışmalı bir konudur. ${ }^{18}$ Geleneksel makaslama ve çekme dayanımı testleri genellikle kırılan seramik restorasyonların kompozit rezinlerle tamirini değerlendirir; bununla birlikte en yaygın olarak kullanılan makaslama testi sıklıkla adezyon bölgesinden uzakta kırılma sağlar. ${ }^{19,} 20$

Makaslama bağlanma dayanımı testi, seramik restorasyonlar ile kompozit rezinin tamirinin değerlen- dirildiği çalışmalarda sıklıkla kullanılmaktadır. ${ }^{21,} 22$ Kalra ve arkadaşları ${ }^{23}$ ağız içi tamir materyali için gerekli olan minimum bağlanma dayanım değerinin çiğneme kuvvetleri ile orantılı olduğu da dikkate alınarak 8-9 MPa olabileceğini bildirmişlerdir. Bu çalışmadan elde edilen bulgular ışığında iki farklı üniversal bağlayıcı ajanın da yeterli tamir bağlanma dayanımı sağladığı görülmektedir.

Üniversal adezivlerin restoratif materyallerdeki tamir bağlanma kuvvetine etkisi farklı çalışmalarla incelenmiştir. Celik ve arkadaşları ${ }^{24}$, Z-Prime Plus kullanılan tamir kiti ile bir üniversal adezivi (Single Bond Universal) karşılaştırmışlar ve zirkonya tamirinde üniversal adezivin daha üstün olduğunu göstermişlerdir. Seabra ve arkadaşları ${ }^{25}$, zirkonya tamirinde Z-Prime Plus ve iki üniversal adezivi (All Bond Universal ve Scothbond Universal) karşılaştırmışlar ve makaslama bağlanma dayanımı üzerinde Z-Prime Plus'ın ancak 2 tabaka halinde uygulanmasının üniversal adezivler kadar etkili olduğunu bulmuşlardır. Ayrıca Z-prime Plus ile örneklerin tamamında adeziv başarısızlık gözlenmiştir. Benzer sonuçlar mevcut çalışmada e.max CAD için de görülmektedir.

Primer kullanımının farklı materyaller üzerinde farklı etkileri olabilir. Mevcut çalışmaya benzer şekilde, CAD/CAM tam seramiklerin üniversal adezivler ile tamiri sonrası bağlanma kuvveti ile ilgili herhangi bir çalışma bulunamadı. Fornazari ve arkadaşları ${ }^{26}$, nanofil kompozitin (Filtek Supreme Ultra) üniversal adezivle tamirinde primer uygulamasının (Ceramic Primer), tek başına üniversal adeziv uygulamasından daha olumlu sonuçları olduğunu ortaya koymuştur. Mevcut çalışmada ise Z-Prime Plus uygulamasının istatistiksel olarak herhangi bir fark oluşturmadığı görülse de, ortalama bağlantı dayanım değerlerini düşürdüğü sonucuna varılmıştır.

\section{SONUÇ}

Bu çalışmanın sınırları dahilinde;

- Üniversal bağlayıcı ajanların tek başına kullanıldığı kontrol grubunun, BISCO Z-Prime Plus kullanılan gruplara benzer bağlanma sonuçları gösterdiği ve iki uygulamanın da klinik olarak yeterli bağlanma dayanımı sağladıkları belirlenmiştir.

- Üniversal bağlayıcı ajanlar, CAD/CAM seramiklerin kompozit rezin ile tamirinde klinik olarak tek başlarına kullanılabilir. 
Uygulanan bağlayıcı ajanların, zirkonyumla güçlendirilmiş lityum silikat seramiğin kompozit rezinle tamirinde lityum disilikat seramiğe göre daha başarılı olduğu bulunmuştur.

Kübra Cantürk: ORCID ID: 0000-0002-1140-2262

Buket Karalar: ORCID ID: 0000-0002-7855-1246

Ömer Sağsöz: ORCID ID: 0000-0002-6506-537X

Nilgün Seven: ORCID ID: 0000-0003-0690-2200

Nurdan Polat Sağsöz: ORCID ID: 0000-0001-7439-4039

Yusuf Ziya Bayındır: ORCID ID: 0000-0003-0943-1352

\section{KAYNAKLAR}

1. Yüce ŞM, Türk AG. Bilgisayar destekli tasarimbilgisayar destekli üretim ve presleme sistemleriyle üretilen porselen laminat venerlerin kenar ve internal uyumlarinin karşilaştirilmasi: in-vitro çalişma. Atatürk Üniversitesi Diş Hekimliği Fakültesi Dergisi, 2017, 27: 19-26.

2. Wang YG, Xing YX, Sun YC, Zhao YJ, Lu PJ, Wang $Y$. Preliminary evaluation of clinical effect of computer aided design and computer aided manufacture zirconia crown. Chinese journal of stomatology, 2013, 48: 355-358.

3. Aboushelib MN. Fatigue and fracture resistance of zirconia crowns prepared with different finish line designs. J Prosthodont, 2012, 21: 22-27.

4. Hickel R, Brushaver K, Ilie N. Repair of restorations--criteria for decision making and clinical recommendations. Dent Mater, 2013, 29: 28-50.

5. Sailer I, Pjetursson BE, Zwahlen M, Hammerle $\mathrm{CH}$. A systematic review of the survival and complication rates of all-ceramic and metalceramic reconstructions after an observation period of at least 3 years. Part II: Fixed dental prostheses. Clin Oral Implants Res, 2007, 18 Suppl 3: 86-96.

6. Edelhoff D, Sorensen JA. Tooth structure removal associated with various preparation designs for anterior teeth. Journal of Prosthetic Dentistry, 2002, 87: 503-509.

7. Setcos J, Khosravi R, Wilson N, Shen C, Yang M, Mjor I. Repair or replacement of amalgam restorations: Decisions at a USA and a UK dental school. Operative Dentistry, 2004, 29: 392-397.

8. Hanabusa M, Mine A, Kuboki T, Momoi Y, Van Ende A, Van Meerbeek B, De Munck J. Bonding effectiveness of a new 'multi-mode' adhesive to enamel and dentine. Journal of Dentistry, 2012, 40: 475-484.

9. Neis $C A$, Albuquerque $\mathrm{NL}$, Albuquerque Ide $\mathrm{S}$, Gomes EA, Souza-Filho CB, Feitosa VP, Spazzin $A O$, Bacchi A. Surface treatments for repair of feldspathic, leucite - and lithium disilicatereinforced glass ceramics using composite resin. Braz Dent J, 2015, 26: 152-155.

10. Oh WS, Shen C. Effect of surface topography on the bond strength of a composite to three different types of ceramic. The Journal of prosthetic dentistry, 2003, 90: 241-246.

11. Robbins JW. Intraoral repair of the fractured porcelain restoration. Operative Dentistry, 1998, 23: 203-207.

12. Peumans $M$, Van Meerbeek B, Yoshida $Y$, Lambrechts $P$, Vanherle $G$. Porcelain veneers bonded to tooth structure: an ultra-morphological FE-SEM examination of the adhesive interface. Dent Mater, 1999, 15: 105-119.

13. Colares RC, Neri JR, Souza AM, Pontes KM, Mendonca JS, Santiago SL. Effect of surface pretreatments on the microtensile bond strength of lithium-disilicate ceramic repaired with composite resin. Braz Dent J, 2013, 24: 349-352.

14. Duzyol M, Sagsoz O, Sagsoz NP, Akgul N, Yildiz M. The Effect of Surface Treatments on the Bond Strength Between CAD/CAM Blocks and Composite Resin. Journal of Prosthodontics-Implant Esthetic and Reconstructive Dentistry, 2016, 25: 466-471.

15. Kupiec KA, Wuertz KM, Barkmeier WW, Wilwerding TM. Evaluation of porcelain surface treatments and agents for composite-to-porcelain repair. Journal of Prosthetic Dentistry, 1996, 76: 119-124.

16. Ozcan M, Vallittu PK. Effect of surface conditioning methods on the bond strength of luting cement to ceramics. Dent Mater, 2003, 19: 725-731.

17. Dong JK OS. The microstructure of IPS Empress ceramics according to the heat treatment and the sprue type. J Korean Acad Prosthodont, 1998, 36:73-86.

18. Matsumura $H$, Kato $H$, Atsuta $M$. Shear bond strength to feldspathic porcelain of two luting cements in combination with three surface treatments. Journal of Prosthetic Dentistry, 1997, 78: 511-517.

19. Dellabona A, Vannoort R. Shear Vs Tensile Bond Strength of Resin Composite Bonded to Ceramic.

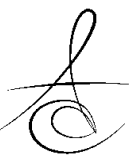


Journal of Dental Research, 1995, 74: 1591-1596.

20. Leibrock $A$, Degenhart $M$, Behr $M$, Rosentritt $M$, Handel G. In vitro study of the effect of thermoand load-cycling on the bond strength of porcelain repair systems. J Oral Rehabil, 1999, 26: 130-137.

21. Sadeghi M, Davari A, Abolghasami Mahani A, Hakimi H. Influence of Different Power Outputs of Er:YAG Laser on Shear Bond Strength of a Resin Composite to Feldspathic Porcelain. J Dent (Shiraz), 2015, 16: 30-36.

22. Lundvall PKR RH, Ekstrand K. . Comparison of different etching agents and repair materials used on feldspatic porcelain. Journal of Adhesion Science and Technology, 2009, 23:1177-86.

23. Kalra A, Mohan MS, Gowda EM. Comparison of shear bond strength of two porcelain repair systems after different surface treatment. Contemp Clin Dent, 2015, 6: 196-200.

24. Celik G, Ismatullaev A, Sari T, Usumez A. Comparison of the Effectiveness of Bonding Composite to Zirconia as a Repair Method. International Journal of Applied Ceramic Technology, 2016, 13: 405-411.

25. Seabra B, Arantes-Oliveira S, Portugal J. Influence of Multimode Universal Adhesives and Zirconia Primer Application Techniques on Zirconia Repair. Journal of Prosthetic Dentistry, 2014, 112: 182187.

26. Fornazari IA, Wille I, Meda EM, Brum RT, Souza EM. Effect of Surface Treatment, Silane, and Universal Adhesive on Microshear Bond Strength of Nanofilled Composite Repairs. Operative Dentistry, 2017, 42: 367-374.

\section{Yazışma Adresi}

Arş. Gör. Dt. Kübra Cantürk

Atatürk Üniversitesi

Diş Hekimliği Fakültesi

Restoratif Diş Tedavisi Anabilim Dalı

25240 Erzurum

e-mail: dt.kubrakulakoglu@gmail.com 